\title{
Accelerating and optimizing global product launches: Using enterprise collaboration technologies to aid project management and market development process
}

\author{
Jan Rothfuss \\ is IT Project Manager, Bausch \& Lomb GSC \& E., Rochester, New York. She currently is supporting the upgrade and \\ expansion efforts for the company's electronic content management system. For the past three years she has \\ supported the ongoing expansion of a collaborative software tool as adopted by the new product development teams. \\ The software was recognized as one of the key "best practices" for its collaborative benefits capability as B\&L was one \\ of five recipients of the American Productivity and Quality Center's award for Best Practices in New Product \\ Development Project Management. Jan holds an MBA from St. John Fisher College, Rochester, New York. She is a \\ certified Project Management Professional (PMP) and is currently pursuing training in the field of design for Six Sigma.
}

\section{Keywords: digital asset management, DAM, collaboration, ROI, new product development, project methodology, content management}

\begin{abstract}
So they tell you that you need to get all of the global project team "on board" as soon as possible knowing that collaboration is critical to the success of the project. But the team is scattered around the globe and is responsible for generating a mountain of documentation, assigned a long list of activities and tasks and must deliver the new product to market on time and on budget. The focus of this paper is the effective use of a software tool to encourage project team collaboration. It discusses the need for a solid new product development methodology and demonstrates the ability to see a fairly quick return on investment (ROI) while assisting in the overall project success.
\end{abstract}

Jan Rothfuss, IT Project Manager Bausch \& Lomb GSC \& E. 1400 N. Goodman St. Rochester, NY 14609 USA

Tel: +15853385587 Fax: +15853380383 Email: jan.rothfuss@ bausch.com

\section{INTRODUCTION}

Bausch \& Lomb Inc. (B\&L) was established in 1854. Its core business includes ophthalmic surgical products, pharmaceutical products and contact lenses/lens care products. In 1999, B\&L reinvented itself, moving from a general healthcare company to a focused eye care company. The company is presently formed around three business units: vision care, surgical and pharmaceutical. The change shifted the company from a decentralized structure to a highly centralized, matrix one.

The change was not smooth. There was a lot of chaos with an inability to perform that showed itself in sales and profitability. The restructuring issues were very pronounced in the research and development $(\mathrm{R} \& \mathrm{D})$ parts of the business. They were now even more global with cross-functional project teams made up of members across the USA and the world. Collaboration 
became even more important as the new product development methodology called for early input by all concerned, timely response by all members and a supportive technical architecture that allowed it all to happen with ease of use.

\section{Business problem}

$\mathrm{B} \& \mathrm{~L}$ shared many of the issues of other companies shifting from a local, decentralized structure to a global one with more of a matrix structure. Global teams were created but they lacked global tools. There was a general lack of information accessibility and a lack of accountability across regions. There were no standards that crossed business units. R\&D project timelines were missed, resulting in delays to market.

The lack of global tools and a strong new product development (NPD) methodology had a significant negative impact on business. This included overly-complicated product planning, high overhead costs for meetings and project budget overruns resulting in significant lag to market and lost revenue opportunities. The $\mathrm{R} \& \mathrm{D}$ pipeline of new products spans many years of development. Too much gap at any point will result in a future point with few or no new products coming to market.

Currently the NPD environment at $\mathrm{B} \& \mathrm{~L}$ includes global teams that involve $600+$ people. An average of 50 products are launched each year with formal project team efforts ranging in duration from a few months to 12 years.

\section{IMPACT OF GLOBAL TOOLS AND NDP METHODOLOGY}

To accelerate and optimize global NPD efforts, B\&L developed a standardized product development management process (PDMP) methodology, a phasegate process to take products from concept through feasibility, development, commercialization, and launch. Global teams require significant project information on a daily basis including budgets, project plans, timelines, activity tracking, lab analyses, test results, and other reports. Although the new methodology defined these requirements more clearly, there were still no collaborative tools in place to make it happen.

\section{Common NPD process defined}

The five-phased, four-gate PDMP methodology was developed and adopted by all three business units. It brought together all ten functional groups in such as way as to make them more accountable to one another in a more timely fashion. Involved at an early point in the project were Engineering, Quality, Chemistry, Information Technology (IT), Regulatory, Finance, Marketing, Program Management and Administration. Each phase of the process had clearly defined functions being performed, including deliverables which were to be created, reviewed and approved before the project could pass through the gate leading to the next phase (see Figure 1).

Many details are needed to describe the activities and deliverables of each PDMP phase fully; highlights include:

- Phase 1: Concept

- Discussions

- Team assignments

- Strategic brief

- Phase 2: Feasibility

- Proof of concept 


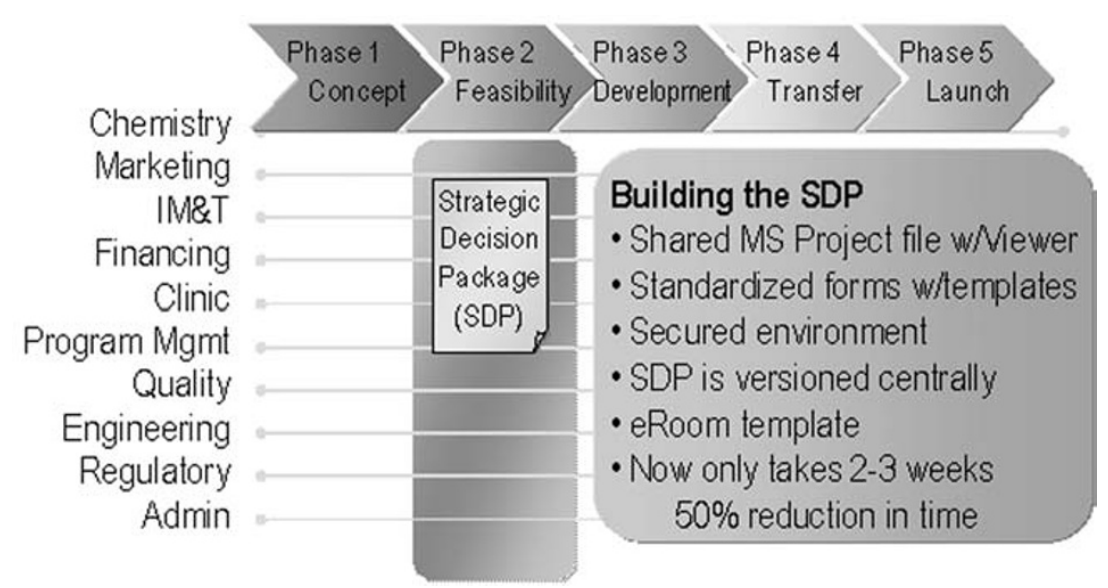

Figure 1: New product development process

- Project plan

- Strategic decision package

- Phase 3: Development

- Scale-up

- Implementation

- Clinical investigation

- Full design review

- Phase 4: Transfer

- Validation

- Final specifications

- Clinical approval

- Updated strategic decision package

- Formal review

- Phase 5: Product launch

- Documentation completion

- Full production implementation

- Project closure

\section{Strategic design package}

One key collaborative effort is the team's preparation of a critical document known as the strategic decision package (SDP). It requires every team member's input and approval and will eventually be signed off, in most cases, by the company CEO. Before such a collaborative tool was in place, this review and approval process was initiated as a file attachment to an email. This generated multiple copies of the document containing various changes. The document coordinator would have to collate the sets of changes back in to the document. No one could see each other's changes until the next review cycle was initiated. This process included multiple team meetings and member travel. This review cycle would be repeated with the whole process taking four to six weeks.

\section{Collaborative tool introduced}

With the enterprise collaborative application in place, the SDP could now be shared, allowing the set of authors and reviewers access to the file in a controlled manner. Standardized forms and templates assisted and encouraged the common process. The environment was secured with user login credentials with each document versioned to track changes and allow for file recovery.

The use of the tool also improved other aspects of the project team's logistics. The Microsoft Project Viewer tool allows the team to share the project work breakdown structure even if they 
do not have MS Project on their PCs. There is also a web-based eMeeting capability provided for "virtual" team meetings allowing documents to be created, shared and revised during team sessions while everyone remains at their base locations. Using this tool decreased time needed to review and approve the SDP document - in many cases 50 per cent less time was required. As this is a repetitive process found in four of the five methodology phases, this has a significant impact on the project timeline.

\section{Lessons learned}

1. To accelerate and optimize global new product development efforts, B\&L developed a standardized product development management process methodology, a phase-gate process to take products from concept through feasibility, development, commercialization, and launch. This evolving methodology requires intensive collaboration among cross-functional team members, including representatives from Operations, Engineering, Packaging, Marketing, Quality, Regulatory affairs, and other departments. These global teams require significant project information on a daily basis including budgets, project plans, timelines, activity tracking, lab analyses, test results, and other reports.

2. Early participation of all functional representatives related to the project is vital. Some can simply observe within the collative environment, reading meeting minutes and reviewing completed documentation until the point where they feel they need to become more active. When more participation is needed, they are already informed and ready to "hit the ground running."

3. With all project information residing in one central, well-organized location, the post launch learning process is now much more productive as well. It is much easier to review what worked and what didn't, what additional information could have helped, how a template should be tweaked, and so on, so future launches can benefit.

Retrieving documents to comply with Food and Drug Administration (FDA) and International Organization for Standardization (ISO) audits is also much easier.

4. Ownership of the system must be shared between the R\&D and IT departments. The adoption and full use of the system relies on the support of both the end users and the necessary technical groups. The software provides the services that are needed to the B\&L teams as well as external suppliers and contractors/ consultants. Security must be maintained. Expansion must be possible not only from the standpoint of room for more artifacts and new users but the ability to expand across to completely new repositories and provide for the expansion and archiving of the repositories that might need to be referenced in the future.

\section{ROI}

\section{Cost savings}

It has been demonstrated that the use of our collaborative tool at $\mathrm{B} \& \mathrm{~L}$ reduces 
the number of full team meetings and related travel necessary for the SDP to be finalized. During what had been a four-week review and approval time for the SDP document, an average of 15 people would gather multiple times. On average, our tool allows for one less meeting per week. Considering each of the 15 people, with their time valued at $\$ 150 /$ hour, with a four-week review period, a total of $\$ 9,000$ is saved per project. With 40 product teams meeting during a given year, the total ROI realized for these meetings is $\$ 360,000$.

In addition, fewer face-to-face meetings needed for each project per year realizes further cost savings. Considering the global nature of the team, an average of $\$ 2,000$ in travel costs per team member has been used. Even if just one meeting per year, per project team is considered, the 40 project teams would realize a saving of $\$ 1.2 \mathrm{~m}$ in meeting expenses.

\section{Revenue savings}

In addition to the two cost savings impacts described previously, there is another ROI tied to the revenue impact: the sooner a company can bring a new product to market, the sooner sales will be recorded.

If we consider that a new product will bring in $\$ 1.0 \mathrm{~m}$ in revenue per year, this comes to about $\$ 19,000$ per week. We learned earlier that there is reduction of four weeks in the timeline as a result of using enhanced collaboration to reduce the review/approval time of the SDP. This translates into $\$ 76,000$ of revenue for every product with a $\$ 1 \mathrm{~m}$ opportunity. Again, this is just one project being considered.

\section{Summary}

To summarize the ROI for a given product as related to collaboration savings, there is an opportunity saving of $\$ 9,000$ (one less review meeting per week), $\$ 30,000$ cost saving (one less global team meeting needed per year) and $\$ 76,000$ per $\$ 1 \mathrm{~m}$ in revenue impact (bringing the new product to market four weeks earlier). Applying these metrics to a product that takes one year to develop and yields $\$ 6 \mathrm{~m}$ revenue, this would then represent an opportunity of $\$ 456,000$ (see Figure 2).

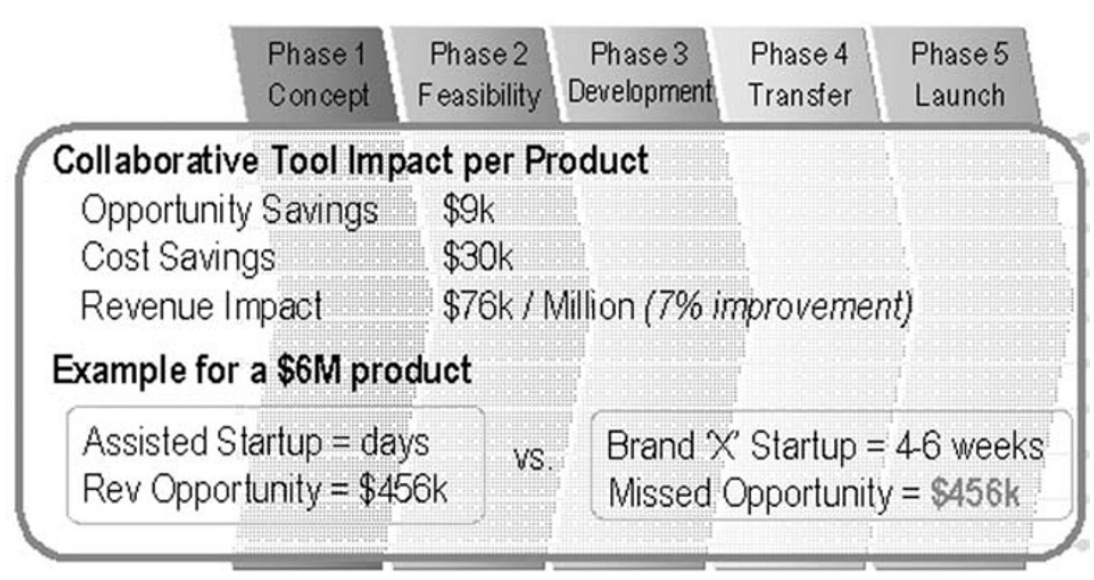

Figure 2: Summary of ROI for B\&L 


\section{CONCLUSION}

The introduction of a collaborative tool provides an enterprise-level solution that is robust, secure and extendable. $\mathrm{B} \& \mathrm{~L}$ used the tool's out-of-the-box functionality for a quick start-up and a minimal learning curve while providing seamless powerful functionality to the end user.

The first step was to develop, and continue to develop, a solid NDP methodology to encourage project team collaboration. B\&L now works locally while being globally aware, minimizing a "head in the sand" syndrome while encouraging collaboration and team ownership, allowing everyone to readily see that they play an important role on the project and that their involvement is critical to success. 